\title{
Construção de escala combinada para a medição do alfabetismo em contexto não escolar
}

\author{
VERA MASAGÁO RIBEIRO* \\ TUFI MACHADO SOARES **
}

\section{RESUMO}

Este artigo descreve o desenvolvimento de uma escala de proficiência para mediçáo do alfabetismo de populaçóes brasileiras jovens e adultas, combinando habilidades de leitura e habilidades matemáticas. A escala foi desenvolvida com base em dados coletados pelo Indicador Nacional de Alfabetismo Funcional (Inaf), que de 2001 a 2007 realizou seis estudos com aplicação de testes de proficiência a amostras representativas da população brasileira de 15 a 64 anos de idade, por meio de entrevistas domiciliares. Primeiramente, são apresentadas algumas referências internacionais de estudos congêneres, com destaque para as opçôes metodológicas adotadas na definição dos domínios compreendidos pelo alfabetismo. Depois, faz-se um breve histórico dos avanços metodológicos realizados pelo Inaf desde seu lançamento e das bases que levaram à proposição de uma escala combinada. Apresentam-se então as análises psicométricas e conceituais que fundamentam a proposição da escala combinada, a descrição dos níveis de alfabetismo definidos a partir dela e alguns resultados obtidos de 2001 a 2007 com a amostra nacional de jovens e adultos.

Palavras-chave: alfabetização, leitura, matemática, escala de avaliação, educação de adultos.

* Pesquisadora da ONG Ação Educativa (vera@acaoeducativa.org).

** Professor do Programa de Mestrado e Doutorado em Educação e Coordenador de Pesquisa do Centro de Políticas Públicas e Avaliação da Educação - Caed da Universidade Federal de Juiz de Fora - UFJF (tufi@caed.uff.br). 


\title{
RESUMEN
}

Este artículo describe el desarrollo de una escala de competencia que combina habilidades de lectura y habilidades matemáticas para la medición del alfabetismo de poblaciones brasileñas de jóvenes y adultos. La escala fue desarrollada a partir de datos relevados por el Indicador Nacional de Alfabetismo Funcional (Inaf), que de 2001 a 2007 realizó seis estudios aplicando tests de competencia a muestras representativas de la población brasileña de entre 15 y 64 ańos de edad, por medio de encuestas domiciliarias. En primer lugar, se presentan algunas referencias internacionales de estudios semejantes, con énfasis en las opciones metodológicas empleadas para definir los dominios comprendidos por el alfabetismo. Después, se hace un breve histórico de los avances metodológicos realizados por el Inaf desde sus orígenes y de los estudios que llevaron a proponer una escala combinada. Para finalizar, se presentan los análisis psicométricos y conceptuales que fundamentan la adopción de la escala combinada, la descripción de los niveles de alfabetismo definidos a partir de ella y algunos resultados obtenidos entre 2001 y 2007 en la muestra nacional seleccionada de jóvenes y adultos.

Palabras clave: alfabetización, lectura, matemática, escala de evaluación, educación de adultos.

\begin{abstract}
This paper describes the development of a scale to measure the proficiency of literacy among the young and adult Brazilian populations, combining reading skills with mathematical skills. The scale was developed based on data collected by Inaf - National Indicator of Functional Literacy, which from 2001 to 2007 held six studies testing literacy proficiency in the Brazilian population between 15 to 64 years of age, through home interviews. First, some references to international similar studies are presented with an emphasis on the methodology adopted for the areas covered by the definition of literacy. Next, a brief history of methodological advances made by Inaf since its launch and the groundwork that led to the proposition of a combined scale are discussed. Finally, we show the psychometric and conceptual analysis which motivated the proposition of the combined scale, the literacy levels defined based on this scale and some results obtained from 2001 to 2007 with a national sample of youngsters and adults.
\end{abstract}

Keywords: literacy, reading, mathematics, evaluation scale, adult education. 


\section{INTRODUÇÃO}

Um dos principais legados que a escola deixa para as pessoas que por ela passam, por vários anos, consiste na possibilidade de se inserirem, de forma autônoma, na cultura letrada, na qual a linguagem escrita é meio privilegiado de informação, comunicação, planejamento e aprendizagem. Nos países industrializados, onde o ensino secundário já estava praticamente universalizado no último quarto do século passado, o interesse em verificar a capacidade da populaçáo adulta de usar a leitura e as operaçóes matemáticas para responder às demandas de seu contexto reorientou as atençóes antes dedicadas ao problema do analfabetismo absoluto. $\mathrm{O}$ conceito de alfabetismo funcional (functional literacy), disseminado internacionalmente pela Unesco a partir da década de 1960, representou um primeiro esforço de superar uma abordagem dicotômica centrada na contraposição entre os que conhecem ou náo os rudimentos da escrita, destacando a necessidade de considerar quanto as pessoas efetivamente usam suas capacidades letradas (Soares, 1995).

As expectativas em relação ao grau de domínio da leitura, escrita e matemática, necessário para uma inserção adequada na cultura letrada, se ampliam consideravelmente à medida que o domínio de sistemas simbólicos se torna mais decisivo na atividade produtiva e a participaçáo cidadá mais condicionada pelo acesso às mídias e às estruturas burocráticas. Nas estatísticas educacionais, certa quantidade de anos de estudo - oito ou nove nos países industrializados, quatro nos países mais pobres - passou a ser utilizada como indicador proxi das condiçóes de alfabetização funcional da população. Entretanto, estudos sociológicos e avaliaçóes educacionais mostram que os sistemas educacionais reproduzem desigualdades sociais, gerando resultados de aprendizagem muito diferentes para uma mesma quantidade de anos de estudo, segundo a regiáo ou segmento social envolvido. Além disso, com o aumento da expectativa de vida da população, torna-se cada vez mais relevante também saber até que ponto as capacidades, uma vez adquiridas na escolarização, se mantêm e se desenvolvem durante a vida e quais são as condiçóes que as favorecem.

\section{REFERÊNCIAS INTERNACIONAIS}

Os EUA e o Canadá foram pioneiros na realização de pesquisas amostrais sobre o alfabetismo da população adulta, utilizando a Teoria da Resposta ao Item (TRI) para analisar níveis de habilidades de leitura e matemática requeridas em contextos cotidianos (Kirsch; Jungeblut, 1986; Montigny; Kelly; Jones, 1991). Tais estudos procuraram se afastar de uma concepçáo estritamente escolar da leitura, evidenciando que os usos sociais das linguagens escritas exigem náo apenas o pro- 
cessamento de textos em prosa, mas também de textos esquemáticos (tabelas, quadros, gráficos, plantas, etc.), que incluem informação tanto verbal quanto numérica. Procurando abarcar essa diversidade, tais pesquisas delimitaram três domínios de habilidades - compreensão de textos em prosa, de textos esquemáticos e de textos quantitativos - criando para cada um deles uma escala e uma descrição qualitativa de níveis de proficiência.

Utilizando essa metodologia desenvolvida nos EUA, a Organização para Cooperação Econômica e Desenvolvimento (OECD) e o Instituto de Estatística do Canadá conduziram uma primeira iniciativa internacional, o International Adult Literacy Assessment (IALS), que, entre 1994 e 1998, recolheu dados comparativos de 19 países, quase todos da Europa e América do Norte. No IALS, o termo analfabetismo nem sequer aparece, pois seu foco é definir e comparar, entre populaçóes com alto grau de escolaridade, níveis de habilidade de alfabetismo em diversos domínios - compreensão de prosa, textos esquemáticos e quantitativos - além de reunir amplo conjunto de dados sobre usos da leitura e da escrita na vida diária, especialmente no contexto de trabalho, e outras informaçóes sobre a inserção profissional, oportunidades de capacitação, renda, etc. (OECD; Statistics Canada, 2000). Em 2003, o estudo começou a mensurar, diretamente, também habilidades de resolução de problemas, passando a se chamar Adult Literacy and Life Skills Survey (ALL). No primeiro relatório do ALL, os autores reafirmam essa nova perspectiva: não se trata de distinguir analfabetos de alfabetizados; o alfabetismo é concebido como fenômeno multidimensional, envolvendo contínuos de proficiência medidos por meio de escalas, cuja interpretação permite indicar o que os adultos são capazes de realizar a cada nível (OECD; Statistics Canada, 2006). Em 2005, a Unesco passou a conduzir uma iniciativa visando adaptar essa mesma metodologia de estudo do alfabetismo para países pobres, com índices muito mais baixos de escolarização: além de analisar mais detalhadamente os níveis mais baixos de proficiência nos três domínios do IALS, o Literacy Assessment and Monitoring Programme (LAMP) se propóe a estudar também o que se chama de habilidades componentes da alfabetização identificação de letras e palavras, fluência e vocabulário -, com a intenção de criar uma escala para cada uma delas (Unesco, 2005).

Nos relatórios do IALS, a descrição dos níveis de proficiência é feita separadamente para cada escala, com uma lista de habilidades que os sujeitos demonstram dominar em cada nível e em cada domínio. Já para as análises das correlaçóes entre desempenho e variáveis sociodemográficas, trajetória escolar e inserção profissional e cidadã são usadas também escalas combinadas, construídas com base 
na análise conjunta dos itens de mais de um domínio. Procedimento semelhante também é utilizado em outra iniciativa da OECD, o Pisa, que, apesar de focalizar a população estudantil, se propóe a medir competências úteis para a inserção social, empregando também o termo literacy, traduzido por letramento na edição brasileira (OECD, 2006). O Pisa mede competências em três domínios: leitura, matemática e ciências, e, no caso da leitura, o desempenho dos estudantes é ainda analisado por meio de três subescalas definidas de acordo com o tipo de tarefa de leitura requerida: "recuperação de informação", "interpretação de textos" e "reflexão e avaliação”.

\section{UMA INICIATIVA BRASILEIRA}

No Brasil, a única medida de alfabetismo da população adulta baseada em surveys, com medição direta de habilidades por meio de testes, além de coleta de informaçôes detalhadas sobre práticas de leitura, escrita e cálculo matemático na vida diária, é o Indicador Nacional de Alfabetismo Funcional (Inaf), iniciativa de duas organizaçóes não-governamentais brasileiras: a Ação Educativa e o Instituto Paulo Montenegro ${ }^{1}$. O objetivo dessas organizaçóes, ao idealizar o Inaf, foi oferecer à sociedade informaçóes sobre as condiçóes de alfabetismo da população adulta brasileira, com vistas a fomentar o debate público a respeito do tema e subsidiar a formulação de políticas de educação e cultura (Ribeiro, 2003). De 2001 a 2007, foram realizados seis levantamentos em amostras de 2 mil pessoas, representativas da populaçáo brasileira de 15 a 64 anos em todas as regiôes do país, das zonas urbanas e rurais.

Até 2005, a medição da proficiência no Inaf era realizada por meio da aplicaçáo alternada e sucessiva de dois testes, um de leitura, contendo 20 itens, e outro de matemática, com 36. Os resultados dos testes eram analisados com base na teoria clássica, levando em conta o total de acertos de cada indivíduo e as características dos itens acertados por eles em cada faixa de escore total. Com base nessa análise, caracterizaram-se quatro níveis, o primeiro referia-se à condição de analfabetismo e os demais, a três níveis de alfabetismo: rudimentar, básico e pleno. As tarefas

\footnotetext{
1 A Ação Educativa tem com missão a defesa de direitos educacionais; atua na área de pesquisa e informação, desenvolvimento de programas de educação de adultos, mobilização social e advocacy. O Instituto Paulo Montenegro é ligado a uma grande empresa de pesquisa que atua em toda a América Latina - o Ibope - e tem como objetivo canalizar recursos financeiros e técnicos da empresa e de terceiros para iniciativas de interesse social, sem finalidade lucrativa.
} 
que serviram para caracterizar cada nível de habilidade foram aquelas realizadas corretamente por pelo menos $75 \%$ das pessoas naquela faixa de escore total. Em 2006, a equipe do Inaf dedicou-se ao aperfeiçoamento da metodologia utilizada. Introduziu a TRI, de modo a viabilizar o desenvolvimento de instrumentos de avaliação mais precisos e flexíveis. Com base em estudo especial feito com a população carcerária paulistana (Instituto Paulo Montenegro e Fundação Prof. Dr. Manoel Pedro Pimental, 2006), testou-se, pela primeira vez, a possibilidade de se abordar as habilidades de leitura e matemática como uma única dimensão cognitiva. Em 2007, a partir da aplicação de teste que incluía itens de leitura e matemática em amostra representativa da população brasileira, a equipe passou a trabalhar na interpretação de uma escala desenvolvida com base na análise integrada desses dois conjuntos de itens, procurando identificar as semelhanças existentes nas habilidades cognitivas desses dois domínios em cada nível da escala.

\section{JUSTIFICATIVAS PARA A CONSTRUÇÃO DA ESCALA COMBINADA E SUAS POSSÍVEIS APLICAÇÕES}

A definição operacional do alfabetismo adotada pelo Inaf, semelhante à consagrada nos estudos internacionais mencionados anteriormente, refere-se à capacidade de compreender, utilizar e julgar informaçóes contidas em materiais escritos de uso corrente (textos contínuos expositivos ou narrativos, gráficos, tabelas, mapas, anúncios, títulos, etc.), para alcançar objetivos, ampliar conhecimentos e participar da sociedade. Trata-se, portanto, de um único constructo, o alfabetismo, no qual se distinguem dois domínios: o primeiro, que passou a ser designado de letramento, refere-se à capacidade de processar informação verbal; o segundo, denominado numeramento, diz respeito à capacidade de processar informação numérica e quantitativa, lançando mão das operaçóes cognitivas específicas que tal processamento envolve. Os sistemas de representação e as operaçóes cognitivas implicadas nas tarefas relativas a cada um dos domínios têm alguns aspectos comuns e outros muito específicos; entretanto, como ambos se referem ao alfabetismo, supôs-se que seria possível construir uma única escala para mensurá-los de forma combinada, mantendo as anteriores como subescalas do letramento e do numeramento.

Já se sabia, com base em estudos realizados com adultos em contextos não escolares, que o desempenho em leitura e matemática estão fortemente correlacionados. Interessava, entâo, saber se haveria fundamento psicométrico na combinação desses dois domínios numa única escala e, também, se haveria aspectos 
qualitativos comuns nas habilidades de letramento e numeramento, num mesmo nível de proficiência. Poderíamos ter, assim, uma medida sintética do alfabetismo, além das duas medidas produzidas por meio das subescalas, cuja validade náo seria comprometida, uma vez que com a utilização da TRI se pode ampliar indefinidamente o número de itens testados em cada um desses domínios. A escala combinada, por sua vez, mais sintética e abrangente no que se refere às capacidades de processamento de informação requeridas pela vida diária, poderia ser extremamente útil para as análises dos resultados do Inaf, que exploram as correlaçóes do alfabetismo com outras variáveis. Acredita-se que a metodologia desenvolvida e validada por levantamentos realizados com amostras representativas da população adulta brasileira pode ser útil para outros estudos que pretendam se valer de medição direta de habilidades para analisar a relação entre educação e inserção profissional, saúde, cidadania ou consumo cultural, por exemplo, nas áreas de sociologia, economia, comunicaçáo, entre outras.

\section{ANÁLISE PSICOMÉTRICA}

Para a definiçáo da escala combinada de alfabetismo, tomou-se como base o teste do Inaf aplicado em 2007 a uma amostra representativa da população brasileira de 15 a 64 anos. A essa amostra, composta por 2002 sujeitos, foi aplicado um único teste composto por 34 itens, já anteriormente aplicados, 17 de letramento e 17 de numeramento. Esses itens já tinham sido previamente calibrados pela TRI em suas respectivas escalas, de acordo com os resultados das cinco ediçóes anteriores do Inaf e estudos especiais, onde novos itens foram calibrados. Também, 7 itens novos foram aplicados no teste de 2007, de tal forma que para a análise de dimensionalidade foram considerados 41 itens no total.

Todas as análises foram realizadas com auxílio do software TESTFACT (Wilson; Wood; Gibbons, 1998). Inicialmente, foi analisada a consistência interna do teste por meio de estatísticas clássicas. Observando as estatísticas obtidas para a correlação bisserial dos itens, pode-se afirmar que os itens são bons quanto à capacidade de discriminação e muito consistentes com os resultados globais do teste. Normalmente, o valor mínimo admissível para a correlaçáo bisserial varia entre 0,2 e 0,3 , e no teste do Inaf o menor valor encontrado foi 0,314 . Os itens também apresentam boa distribuição quanto ao nível de dificuldade, variando o porcentual de acerto de $14 \%$ até $85 \%$. A consistência interna (a fidedignidade) do teste parece ser muito boa, o que fica caracterizado pela estatística alfa de Cronbach de cerca de 0,9. A disposição das questóes no teste, aumentando gradativamente 
o grau de dificuldade, favorece as respostas dos indivíduos e é adequada aos objetivos do Inaf. Por outro lado, tanto os itens mais fáceis quanto os mais difíceis apresentam alta discriminação, implicando uma boa capacidade de informação do teste nos diversos níveis de proficiência que serão estimados, o que pode ser visto na figura 1.

Figura 1 - Resultados da análise clássica dos itens do Inaf

\begin{tabular}{|c|c|c|c|c|c|c|c|c|}
\hline ITEM & NUMMER & MEAN & S.D. & RMEAN & FACILITY & DIFF & BIS & P.BIS \\
\hline 1001 & 2002 & 18.34 & 10.24 & 19.91 & 0.853 & 8.81 & 0.568 & 0.369 \\
\hline$\frac{1}{2} 002$ & 2002 & 18.34 & 10.24 & 20.93 & 0.815 & 9.42 & 0.771 & 0.530 \\
\hline 3003 & 2002 & 18.34 & 10.24 & 24.23 & 0.531 & 12.69 & $0.76 \overline{9}$ & 0.613 \\
\hline 4004 & 2002 & 18.34 & 10.24 & 24.96 & 0.438 & 13.63 & 0.718 & 0.570 \\
\hline 5005 & 2002 & 18.34 & 10.24 & 22.83 & 0.696 & 10.94 & 0.874 & 0.665 \\
\hline 6006 & 2002 & 18.34 & 10.24 & 23.29 & 0.684 & 11.08 & 0.931 & 0.712 \\
\hline 7007 & 2002 & 18.34 & 10.24 & 26.17 & 0.376 & 14.27 & 0.757 & 0.593 \\
\hline 8008 & 2002 & 18.34 & 10.24 & 25.89 & 0.445 & 13.55 & 0.831 & 0.661 \\
\hline 9009 & 2002 & 18.34 & 10.24 & 28.26 & 0.249 & 15.71 & 0.761 & 0.558 \\
\hline $10 \quad 010$ & 2002 & 18.34 & 10.24 & 24.78 & 0.458 & 13.43 & 0.725 & 0.577 \\
\hline 1101 & 2002 & 18.34 & 10.24 & 23.21 & 0.585 & 12.14 & 0.714 & 0.565 \\
\hline $\begin{array}{lll}12 & 012\end{array}$ & 2002 & 18.34 & 10.24 & 24.92 & 0.501 & 12.98 & 0.807 & 0.644 \\
\hline$-13 \quad 013$ & 2002 & 18.34 & 10.24 & 26.38 & 0.354 & 14.50 & 0.747 & 0.581 \\
\hline $14 \quad 014$ & 2002 & 18.34 & 10.24 & 28.29 & 0.228 & 15.98 & 0.734 & 0.529 \\
\hline 15015 & 2002 & 18.34 & 10.24 & 28.55 & 0.231 & 15.94 & 0.757 & 0.547 \\
\hline $16 \quad 016$ & 2002 & 18.34 & 10.24 & 25.06 & 0.520 & 12.80 & 0.856 & 0.683 \\
\hline$-17 \quad 017$ & 2002 & 18.34 & 10.24 & 24.10 & 0.620 & 11.78 & 0.915 & 0.718 \\
\hline 18018 & 2002 & 18.34 & 10.24 & 22.35 & 0.673 & 11.20 & 0.731 & 0.562 \\
\hline 19019 & 2002 & 18.34 & 10.24 & 22.23 & 0.704 & 10.86 & 0.773 & 0.585 \\
\hline $20 \quad 020$ & 2002 & 18.34 & 10.24 & 20.35 & 0.881 & 8.29 & 0.866 & 0.532 \\
\hline 21 Q21 & 2002 & 18.34 & 10.24 & 23.63 & 0.579 & 12.20 & 0.765 & 0.606 \\
\hline $22 \quad 022$ & 2002 & 18.34 & 10.24 & 25.24 & 0.428 & 13.73 & 0.736 & 0.583 \\
\hline $23 \quad 023$ & 2002 & 18.34 & 10.24 & 20.92 & 0.841 & 9.00 & 0.874 & 0.579 \\
\hline $24 \quad 024$ & 2002 & 18.34 & 10.24 & 24.29 & 0.578 & 12.21 & 0.859 & 0.680 \\
\hline $25 \quad 025$ & 2002 & 18.34 & 10.24 & 26.91 & 0.337 & 14.69 & 0.772 & 0.596 \\
\hline 26026 & 2002 & 18.34 & 10.24 & 26.19 & 0.331 & 14.75 & 0.699 & 0.539 \\
\hline $27 \quad 027$ & 2002 & 18.34 & 10.24 & 24.95 & 0.424 & 13.77 & 0.699 & 0.554 \\
\hline 28028 & 2002 & 18.34 & 10.24 & 24.36 & 0.571 & 12.2 & 0. & 0.679 \\
\hline 29029 & 2002 & 18.34 & 10.24 & 26.67 & 0.370 & 14.33 & & 0.623 \\
\hline $30 \quad 030$ & 2002 & 18.34 & 10.24 & 25.75 & 0.267 & 15.48 & 0.588 & 0.437 \\
\hline $31 \quad 031$ & 2002 & 18.34 & 10.24 & 25.35 & 0.453 & 13.47 & 0.783 & 0.623 \\
\hline $32 \quad 32$ & 2002 & 18.34 & 10.24 & 25.91 & 0.418 & 13.83 & 0.790 & 0.626 \\
\hline $33 \quad 033$ & 2002 & 18.34 & 10.24 & 25.56 & 0.430 & 13.71 & 0.771 & 0.612 \\
\hline $34 \quad 034$ & 2002 & 18.34 & 10.24 & 28.69 & 0.188 & 16.54 & 0.705 & 0.487 \\
\hline $35 \quad 035$ & 2002 & 18.34 & 10.24 & 25.40 & 0.134 & 17.43 & 0.428 & 0.271 \\
\hline $36 \quad 036$ & 2002 & 18.34 & 10.24 & 24.17 & 0.088 & 18.40 & 0.314 & $0.17 \overline{7}$ \\
\hline 37037 & 2002 & 18.34 & 10.24 & 26.04 & 0.141 & 17.31 & 0.474 & 0.304 \\
\hline 38038 & 2002 & 18.34 & 10.24 & 25.58 & 0.260 & 15.57 & 0.567 & 0.419 \\
\hline 39039 & 2002 & 18.34 & 10.24 & 24.44 & 0.330 & 14.76 & 0.544 & 0.419 \\
\hline $40 \quad 040$ & 2002 & 18.34 & 10.24 & 28.86 & 0.106 & 17.98 & 0.595 & 0.354 \\
\hline 41041 & 2002 & 18.34 & 10.24 & 26.54 & 0.223 & 16.04 & 0.599 & 0.430 \\
\hline
\end{tabular}

Após a análise clássica dos itens, passou-se à análise da dimensionalidade do teste. Para isso, produz-se uma análise fatorial clássica (método MINRES) que, entre outros aspectos, consiste, inicialmente, na inspeção das chamadas "raízes latentes" para a matriz de correlaçáo tetracórica dos itens do teste. Note-se que o primeiro valor (Figura 2) é claramente muito superior aos demais, um indicativo de que a primeira dimensão é preponderante. 
Figura 2 - Raízes latentes da Matriz de Correlação Tetracórica

\begin{tabular}{|c|c|c|c|c|c|c|}
\hline DISPLAY & THE & CORRECTED & LATENT ROOTS & 5 OF THE & CORRELATION & MÄTRIX \\
\hline & 1 & 2 & 3 & 4 & 5 & 6 \\
\hline \multirow[t]{2}{*}{1} & 21.14554 & 2.67777 & 2.12055 & 1.62360 & 1.41668 & 1.14578 \\
\hline & 7 & 8 & 9 & 10 & 11 & 12 \\
\hline \multirow[t]{2}{*}{1} & 0.85780 & 0.74577 & 0.69683 & 0.59709 & 0.57437 & 0.54896 \\
\hline & 13 & 14 & 15 & 16 & 17 & 18 \\
\hline \multirow[t]{2}{*}{1} & 0.50353 & 0.48781 & 0.47405 & 0.43001 & 0.42539 & 0.40887 \\
\hline & 19 & 20 & 21 & 22 & 23 & 24 \\
\hline \multirow[t]{2}{*}{1} & 0.38725 & 0.36225 & 0.34721 & 0.31798 & 0.30597 & 0.28443 \\
\hline & 25 & 26 & 27 & 28 & 29 & 30 \\
\hline \multirow[t]{2}{*}{1} & 0.26855 & 0.25029 & 0.22518 & 0.22158 & 0.19658 & 0.17748 \\
\hline & 31 & 32 & 33 & 34 & 35 & 36 \\
\hline \multirow[t]{2}{*}{1} & 0.16651 & 0.14853 & 0.11409 & 0.10235 & 0.09579 & 0.05945 \\
\hline & 37 & 38 & & & & \\
\hline 1 & 0.05400 & 0.03412 & & & & \\
\hline
\end{tabular}

Produzindo uma análise fatorial com 4 fatores e utilizando o método MINRES, obteve-se a seguinte partição para variância explicada e as seguintes cargas associadas aos fatores extraídos com o método:

Figura 3 - Porcentual da Variância Explicada, por Fator

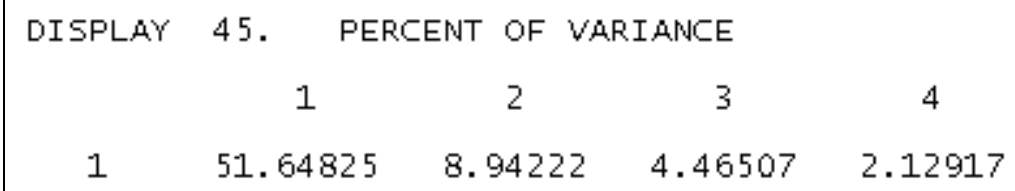


Figura 4 - Cargas Associadas aos Fatores

DISPLAY 40. UNROTATED PRINGIPAL FACTOR LOADINGS

$\begin{array}{llll}1 & 2 & 3 & 4\end{array}$

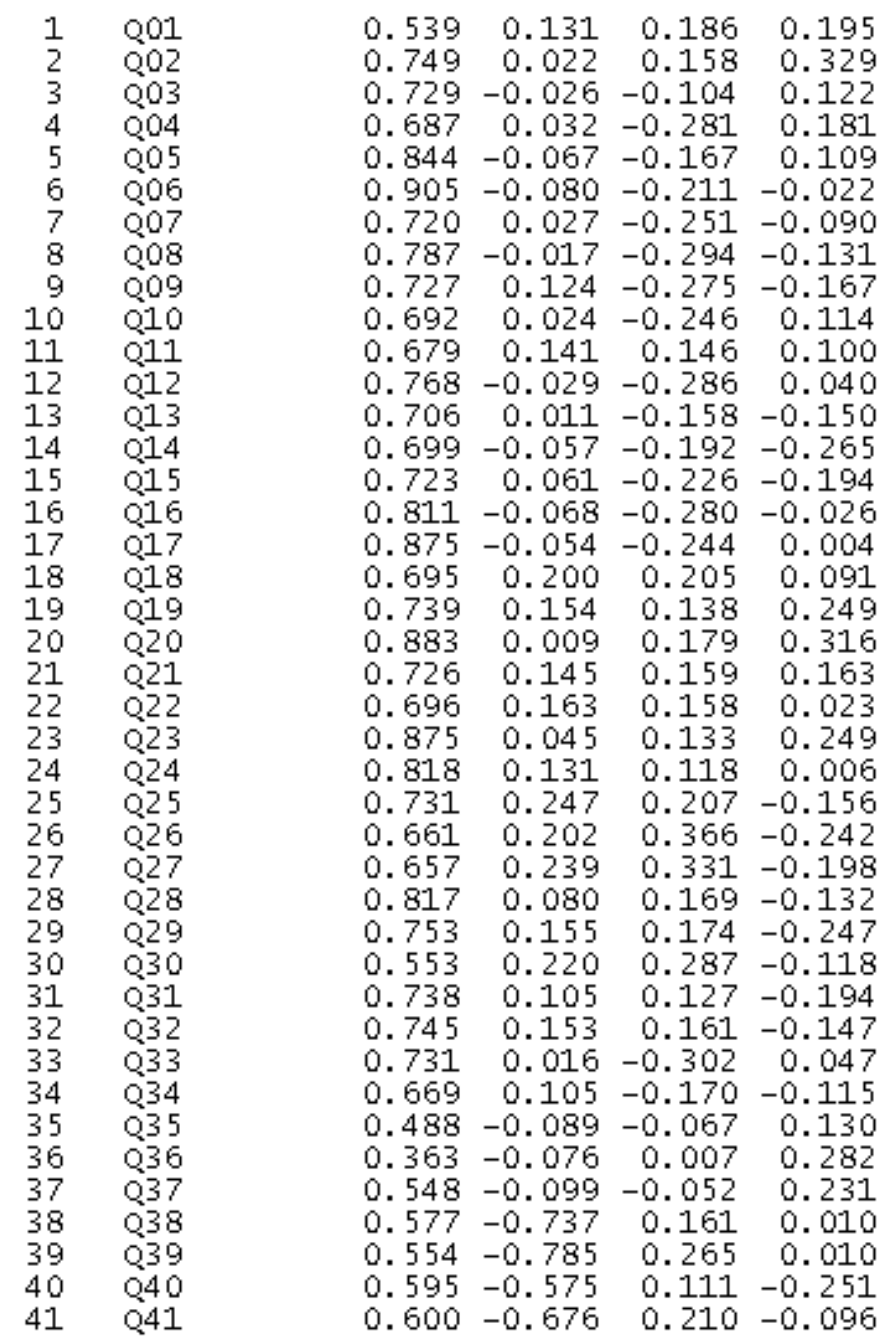

Nota-se que o primeiro fator é amplamente dominante e cerca de 7,5 vezes mais explicativo que o segundo. Observa-se, ainda, que todos os itens apresentam cargas bastante altas no primeiro fator, entendido, então, como a representação da proficiência combinada. Por outro lado, o segundo fator, muito menos importante, caracteriza-se por apresentar cargas mais elevadas com respeito a alguns itens de matemática, indicando, é claro, uma dimensão de matemática, porém muito menos importante que a dimensão combinada. 
Após a análise da dimensionalidade do teste, constatou-se a possibilidade, do ponto de vista de uma análise psicométrica, de se produzir uma escala única e combinada, incluindo os itens de letramento e numeramento. Reforça-se essa conclusão, baseada na análise estatística realizada por especialistas do Inaf em letramento e numeramento.

Dessa forma, tomando como referência o teste de 2007 e utilizando o modelo de dois parâmetros da TRI em grupos múltiplos, calibrou-se todos os 72 itens do Inaf aplicados até então, 30 do domínio do letramento e 42 do numeramento, em uma única escala de proficiências.

\section{ANÁLISE QUALITATIVA DAS HABILIDADES CORRESPONDENTES A CADA NÍVEL DE DIFICULDADE}

Para analisar as habilidades que correspondem a cada nível de proficiência na escala, consideramos o parâmetro máximo de cada item (o ponto mais alto na sua curva de discriminaçáo), que se situa normalmente um pouco abaixo do nível de proficiência, no qual o item atinge $80 \%$ de acertos e sempre acima do ponto em que atinge $75 \%$. Podemos dizer, portanto, que, naquele nível de proficiência, o indivíduo tem aproximadamente $80 \%$ de chance de acertar aquele item, ou que, naquele nível de proficiência, aquela habilidade já está bastante consolidada.

Analisando o conjunto dos 72 itens assim ordenados na escala combinada, definiram-se quatro níveis de proficiência, com base nos pontos onde se verificam mudanças qualitativas nas habilidades características dos itens de letramento e numeramento. Apesar das especificidades de cada um desses domínios, foi possível identificar correspondências entre eles. $\mathrm{Na}$ faixa situada entre o ponto 55 até o ponto $90 \mathrm{da}$ escala, situam-se itens que envolvem somente a leitura de números familiares (preços e horários, por exemplo) ou localização de informaçóes explícitas em sentenças simples. A partir do ponto 90 até o 125, os itens correspondem à capacidade de ler textos curtos e localizar uma informação, mesmo que, para isso, seja necessário realizar pequenas inferências. Os itens de matemática situados nesse nível já compreendem a leitura de números maiores e a realização de uma operação ou domínio de noçóes matemáticas, como a de proporcionalidade. Nesse nível, os sujeitos já realizam operaçóes com a informação textual, mas se trata de operaçóes diretas, que não envolvem diversas etapas, retomadas, conferências ou consideração de vários elementos simultaneamente. A partir dos 125 pontos, os itens já envolvem maior capacidade de estabelecer relaçóes entre informaçóes, realizar mais de uma operaçáo matemática, maior capacidade de análise e maior controle cognitivo, uma 
vez que o processamento da informação envolve a consideração de diversos elementos ou uma seqüência de passos para sua execução. Também a esse nível, corresponde a capacidade de interpretar informaçáo representada por meio de tabelas e gráficos, sobre temas não familiares.

Os sujeitos cuja proficiência fica abaixo de 55 são considerados analfabetos, uma vez que não demonstram domínio de nenhuma das habilidades testadas. O nível que se inicia no ponto 55 foi chamado de alfabetismo rudimentar; a partir do 90, caracteriza-se o nível básico e, a partir do 125, o nível pleno de alfabetismo. O quadro 1 apresenta uma descrição mais detalhada das habilidades que caracterizam cada um desses níveis na escala de alfabetismo.

Depois de analisar os níveis da escala de alfabetismo combinada, voltou-se às subescalas de letramento e numeramento, para realizar a análise com os mesmos critérios. Cada uma dessas escalas foi definida com base somente nos itens correspondentes (30 e 42 respectivamente). Observou-se que, em linhas gerais, a gradação dos níveis de dificuldade mantém-se a mesma e que, com algumas pequenas variaçóes quanto ao ponto de corte, as mesmas descrições qualitativas se aplicam. Assim, a descrição dos níveis na subescala de letramento corresponde à coluna da esquerda do quadro 1 , e os da subescala de numeramento à coluna da direita. O quadro 2 mostra os pontos de corte que definem os níveis de alfabetismo nas três escalas.

$\mathrm{Na}$ tabela 1, é possível comparar as diferenças dos resultados obtidos pelos sujeitos testados no Inaf 2007, quando sua proficiência é medida pela escala de alfabetismo combinado ou pelas duas subescalas. Nesse ano, nenhum sujeito foi classificado como analfabeto na escala do numeramento, ou seja, todos demonstraram a capacidade de ler números familiares, resultado compatível com o de anos anteriores, em que se constataram porcentuais muito pequenos de analfabetismo matemático. Esse índice mostra que os 6,7\% classificados como analfabetos, na escala combinada, correspondem dominantemente aos que não conseguem ler sentenças simples. De fato, a diferença entre o analfabetismo medido na escala combinada de alfabetismo e na sub-escala de letramento é de apenas 1,3 ponto porcentual. Já no nível pleno, a relação se inverte: há uma proporção maior de sujeitos que o atingem na subescala de letramento, e a escala de alfabetismo indica um porcentual intermediário $(28,1 \%)$, ante $26,7 \%$ e $30,0 \%$. Considerando as margens de erro do estudo de 2 pontos porcentuais para cima ou para baixo, a descrição das habilidades de alfabetismo, medidas por meio da escala de alfabetismo, são coerentes com os resultados obtidos pelas subescalas. 
Quadro 1 - Descrição dos níveis de alfabetismo na escala combinada

\begin{tabular}{|c|c|c|}
\hline Nível & Letramento & Numeramento \\
\hline Analfabetismo & \multicolumn{2}{|c|}{ - Não domina as habilidades testadas. } \\
\hline Rudimentar & $\begin{array}{l}\text { - Localiza uma informação } \\
\text { explícita em textos muito simples } \\
\text { e/ou familiares, compostos de } \\
\text { sentenças e palavras (anúncios, } \\
\text { títulos numa capa de revista, } \\
\text { calendário). }\end{array}$ & $\begin{array}{l}\text { - Lê e escreve números familiares, localiza } \\
\text { uma informação numérica evidente em } \\
\text { textos muito simples e de uso corrente } \\
\text { (número de telefone, horário, preços de } \\
\text { produtos em anúncios, cédulas), reúne } \\
\text { notas e moedas para pagar quantia } \\
\text { pequena, faz a medida de um comprimento } \\
\text { usando uma fita métrica. }\end{array}$ \\
\hline Básico & $\begin{array}{l}\text { - Lê um texto de extensão média } \\
\text { (cartas, notícias, avisos } \\
\text { corporativos), localiza uma } \\
\text { informação, podendo fazer } \\
\text { pequenas inferências. Pode } \\
\text { utilizar recursos para se orientar } \\
\text { na leitura, como sumário, } \\
\text { subtítulos e legendas. } \\
\text { - Reconhece referência de } \\
\text { substituição de palavras (por } \\
\text { exemplo, sigla). }\end{array}$ & $\begin{array}{l}\text { - Lê números da ordem dos milhões, resolve } \\
\text { problemas matemáticos envolvendo uma } \\
\text { operação aritmética e a execução de uma } \\
\text { seqüência de ações com pequenas } \\
\text { exigências de planejamento e controle } \\
\text { (calcular valor total de uma compra, calcular } \\
\text { troco, contar dinheiro, calcular valor de } \\
\text { prestações sem juros, compreende noção } \\
\text { de proporcionalidade entre a quantidade } \\
\text { de produto e preço). }\end{array}$ \\
\hline Pleno & $\begin{array}{l}\text { - Localiza vários itens de } \\
\text { informação, compara textos, } \\
\text { identificando semelhanças e } \\
\text { diferenças, seleciona um ou mais } \\
\text { itens de informação com base } \\
\text { em um ou mais critérios, } \\
\text { relaciona e compara } \\
\text { fato/opinião, fonte/versão, infere } \\
\text { palavras substituídas, opera com } \\
\text { informação contra-evidente, } \\
\text { interpreta relacionando } \\
\text { informação textual com } \\
\text { informação não textual. } \\
\text { - Preenche um formulário } \\
\text { retirando informação em mais de } \\
\text { um documento, redige pequena } \\
\text { síntese relativa à interpretação } \\
\text { de textos lidos. }\end{array}$ & $\begin{array}{l}\text { - Resolve problemas em que é necessário } \\
\text { estabelecer critério de seleção de } \\
\text { informações, elaborar e controlar um plano } \\
\text { para produzir a resposta desejada (calcula } \\
\text { valor total de compras envolvendo adições } \\
\text { e multiplicações, calcula desconto } \\
\text { porcentual, resolve problema envolvendo } \\
\text { cálculo proporcional, medida de tempo, } \\
\text { calcula área de superfície retangular). } \\
\text { - Localiza e relaciona mais de uma } \\
\text { informação em tabelas de dupla entrada. Lê } \\
\text { e entende gráficos de setor e colunas, } \\
\text { compreendendo os elementos que } \\
\text { caracterizam essa representação (valores } \\
\text { negativos, relação parte/todo). } \\
\text { - Compreende noção de escala em mapas. }\end{array}$ \\
\hline
\end{tabular}

Quadro 2 - Intervalos que definem níveis de alfabetismo na escala de alfabetismo e sub-escalas de letramento e numeramento

\begin{tabular}{|lccc|}
\hline Nível & Combinada & Letramento & Numeramento \\
\hline Analfabetismo & Menos de 50 & Menos de 50 & Menos de 55 \\
$\begin{array}{l}\text { Alfabetismo } \\
\text { Nível Rudimentar }\end{array}$ & De 50 a menos de 95 & $\begin{array}{c}\text { De } 50 \text { a menos } \\
\text { de } 95\end{array}$ & $\begin{array}{c}\text { De } 25 \text { a menos } \\
\text { de } 90\end{array}$ \\
$\begin{array}{l}\text { Alfabetismo } \\
\text { Nível Básico }\end{array}$ & De 95 a 125 & De 95 a menos & De 90 a menos \\
Alfabetismo 120 & de 120 \\
Nível Pleno & 125 ou mais & 120 ou mais & 120 ou mais \\
\hline
\end{tabular}


Tabela 1 - Níveis de Alfabetismo da População de 15 a 64 anos (Brasil, 2007)

\begin{tabular}{lccc}
\hline Nível & $\begin{array}{c}\text { Escala } \\
\text { Combinada }\end{array}$ & $\begin{array}{c}\text { Subescala de } \\
\text { Letramento }\end{array}$ & $\begin{array}{c}\text { Subescala de } \\
\text { Numeramento }\end{array}$ \\
\hline Analfabetismo & $6,7 \%$ & $8,0 \%$ & - \\
Alfabetismo Nível Rudimentar & $25,5 \%$ & $22,9 \%$ & $26,9 \%$ \\
Alfabetismo Nível Básico & $39,7 \%$ & $39,1 \%$ & $46,4 \%$ \\
Alfabetismo Nível Pleno & $28,1 \%$ & $30,0 \%$ & $26,7 \%$ \\
\hline
\end{tabular}

Fonte: Inaf, 2007.

Para recuperar a série histórica dos dados do Inaf, que vêm sendo coletados desde 2001, os resultados da escala combinada foram projetados para os anos anteriores. Como até 2005 somente itens de letramento foram aplicados nos anos ímpares e somente os de numeramento nos anos pares, analisamos a evoluçáo do índice por meio de uma escala móvel, reunindo em cada ponto as amostras submetidas ao teste de leitura e matemática nos anos subseqüentes. Também, nesse caso, pode-se observar a consistência da medida, que mostra uma evolução nas capacidades de alfabetismo da população.

Tabela 2 - Evolução dos níveis de alfabetismo na escala combinada (Brasil, escala móvel de 2001 a 2005 e 2007)

\begin{tabular}{lccccc}
\hline & $\mathbf{2 0 0 1 - 2 0 0 2}$ & $\mathbf{2 0 0 2 - 2 0 0 3}$ & $\mathbf{2 0 0 3 - 2 0 0 4}$ & $\mathbf{2 0 0 4 - 2 0 0 5}$ & $\mathbf{2 0 0 7}$ \\
\cline { 2 - 6 } BASE & 4.000 & 4.000 & 4.002 & 4.004 & 2.002 \\
Analfabeto & $12 \%$ & $13 \%$ & $12 \%$ & $11 \%$ & $7 \%$ \\
Rudimentar & $27 \%$ & $26 \%$ & $26 \%$ & $26 \%$ & $25 \%$ \\
Básico & $34 \%$ & $36 \%$ & $37 \%$ & $38 \%$ & $40 \%$ \\
Pleno & $26 \%$ & $25 \%$ & $25 \%$ & $26 \%$ & $28 \%$ \\
\hline
\end{tabular}

Fonte: Inaf, 2001 a 2005 e 2007.

A análise por faixa etária sugere que a evolução pode ser resultado tanto da ampliação do acesso e permanência das crianças e adolescentes na escola quanto da ampliação da escolarização dos jovens e adultos, verificada na última década (Ribeiro; Batista, 2006). 
Tabela 3 - Níveis de Alfabetismo da População por faixa etária (Brasil, 2001-2002 e 2007)

\begin{tabular}{lcc|cc|cc|cc}
\hline & \multicolumn{2}{c|}{$\begin{array}{c}\text { De 15 a 24 anos } \\
\text { 2001-2002 }\end{array}$} & \multicolumn{2}{c|}{ De 25 a 34 anos } & \multicolumn{2}{c|}{ De 35 a 49 anos } & \multicolumn{2}{c}{ De 50 a 64 anos } \\
\cline { 2 - 8 } & $\mathbf{2 0 0 1 - 2 0 0 2}$ & $\mathbf{2 0 0 7}$ & $\mathbf{2 0 0 1 - 2 0 0 2}$ & $\mathbf{2 0 0 7}$ & $\mathbf{2 0 0 1 - 2 0 0 2}$ & $\mathbf{2 0 0 7}$ \\
BASE & 1.264 & 573 & 916 & 485 & 1.076 & 528 & 744 & 416 \\
Analfabeto & $3 \%$ & $2 \%$ & $7 \%$ & $3 \%$ & $15 \%$ & $9 \%$ & $29 \%$ & $14 \%$ \\
Rudimentar & $19 \%$ & $14 \%$ & $26 \%$ & $21 \%$ & $31 \%$ & $29 \%$ & $37 \%$ & $41 \%$ \\
Básico & $43 \%$ & $47 \%$ & $35 \%$ & $41 \%$ & $32 \%$ & $37 \%$ & $23 \%$ & $33 \%$ \\
Pleno & $35 \%$ & $37 \%$ & $32 \%$ & $35 \%$ & $22 \%$ & $25 \%$ & $11 \%$ & $12 \%$ \\
\hline
\end{tabular}

Fonte: Inaf, 2001, 2002, 2007.

\section{CONSIDERAÇÕES FINAIS}

A introdução da metodologia da TRI no Inaf abriu uma série de possibilidades e potencializou sua capacidade para mensurar os níveis de alfabetismo da população. A construção de um banco de itens calibrados em escalas de proficiência possibilita, também, que a metodologia seja utilizada com mais flexibilidade para avaliar resultados de aprendizagem de programas de alfabetização e educação básica de jovens e adultos.

É certo que, para a análise pedagógica das competências que compóem o alfabetismo, é útil contar com subescalas específicas de acordo com os domínios letramento ou numeramento - ou mesmo outros ainda mais específicos, como os definidos pelo tipo de texto a ser processado (contínuos e não contínuos), opção adotada pelo IALS e ALL, ou do tipo de tarefa de leitura requerida (localizaçáo, interpretação, avaliação/reflexão) como proposto no PISA. Para tornar possíveis exploraçóes nessa linha, será preciso ampliar o banco de itens calibrados nas escalas do Inaf, de modo a abranger um espectro mais amplo de habilidades. Este é um projeto que já se encontra em curso e deverá mostrar resultados a partir de 2009.

Uma escala única de alfabetismo, por sua vez, dado o seu poder de síntese, pode ser bastante útil especialmente para estudos mais abrangentes sobre os resultados da escolarização e outras oportunidades educativas que promovem o desenvolvimento das habilidades no decorrer da vida. Do ponto de vista pedagógico, também, o conceito de alfabetismo - que abrange a capacidade de processar informação verbal e/ou numérica - pode contribuir para que os educadores superem uma visão limitada da leitura como "conteúdo da disciplina de Língua Portuguesa" ou dos números como "assunto exclusivo da disciplina Matemática", e passem a reconhecer o alfabetismo como competência estruturante, instrumento para as aprendizagens 
dos mais diversos campos do saber e das práticas cotidianas, desenvolvendo um trabalho integrado e estruturado, tendo em vista a gradação das habilidades a serem desenvolvidas durante a educaçáo básica.

\section{REFERÊNCIAS BIBLIOGRÁFICAS} INSTITUTO PAULO MONTENEGRO; FUNDAÇÃO PROF. DR MANOEL PEDRO PIMENTAL. Educação que liberta: indicador de alfabetismo funcional da população carcerária paulista. São Paulo: Funap/Secretaria de Administração Penitenciária, 2006.

KIRSCH, Irwin; JUNGEBLUT, Ann. Literacy: profiles of America's young adults. Princeton: Education Testing Service, 1986.

MONTIGNY, Gilles; KELLY, Karen; JONES, Stan. Adult literacy in Canada: results of a national study. Ottawa: Minister of Industry Science and Thecnology, 1991.

OECD. Assessing cientific, reading and mathematical literacy: a framework for PISA. Paris: OECD, 2006.

OECD; STATISTICS CANADA. Learning a living: first results of the adult literacy and life skills survey. Paris, 2005.
. Literacy in the information age:

final report of the international adult literacy survey. Paris, 2000.

RIBEIRO, Vera Masagão. Letramento no Brasil. São Paulo: Global, 2003.

RIBEIRO, Vera Masagão; BATISTA, Antonio Augusto. L'Alphabetisation au Brésil: réalisation et défits. Éducation des adultes et Développment, Alemanha, n. 67, p. 183-214, 2006.

SOARES, Madga. Língua escrita, sociedade e cultura. Revista Brasileira de Educação, n. 0, p. 5-16, set./dez. 1995.

UNESCO. Standards and guidelines for the design and implementation of the literacy assessment and monitoring programme (LAMP). Montreal: Unesco, 2005.

WILSON, D. T.; WOOD, R.; GIBBONS, R. Testfact: test scoring, and item factor analysis. Scientific Software International. Illinois: Lincolnwood, 1998.

Recebido em: outubro 2008

Aprovado para publicação em: novembro 2008 